\title{
Validation of observed bedload transport pathways using morphodynamic modeling
}

\author{
A. Mineault-Guitard, C.D. Rennie \\ Department of Civil Engineering, University of Ottawa, Ottawa, Ontario, Canada \\ R.D. Williams \\ School of Geographical and Earth Sciences, University of Glasgow, Glasgow, United Kingdom
}

\begin{abstract}
Phenomena related to braiding, including local scour and fill, channel bar development, migration and avulsion, make numerical morphodynamic modeling of braided rivers challenging. This paper investigates the performance of a Delft3D model, in a 2D depth-averaged formulation, to simulate the morphodynamics of an anabranch of the Rees River (New Zealand). Model performance is evaluated using data from field surveys collected on the falling limb of a major high flow, and using several sediment transport formulas. Initial model results suggest that there is generally good agreement between observed and modeled bed levels. However, some discrepancies in the bed level estimations were noticed, leading to bed level, water depth and water velocity estimation errors.
\end{abstract}

\section{INTRODUCTION}

Braided rivers constitute one of the three most common channel types found on Earth (Chalov \& Alexeevsky, 2015). These rivers are characterized by multiple channels, as well as wide active and mostly un-vegetated widths. Braiding can be mesmerizing since flow and sediment transport interact and are able to change morphology in a rapid and complex fashion. Generally, braiding occurs due to high sediment supply in a channel or a river (Church, 1992). Processes involved include local scour and fill, channel bars development and migration, as well as bifurcation mechanisms. The phenomena listed above are generated due to high stream power as well as low bed and bank erosion resistance relative to stream energy (Ashmore 2013, Belletti et al. 2015).

The physical mechanisms of braiding make numerical modeling, more specifically sediment and bedload modeling, of this river style challenging. Some of the challenges faced when modeling braided rivers include the spatial and temporal scales of morphodynamics. A model's spatial resolution and comparable extent, temporal frequency and accuracy of observational data for calibration can lead to other difficulties. Conventional topographical channel surveys are done such that larger areas are analyzed to obtain coarse data, while high resolution data is gathered for small areas (Li et al., 2008). However, the use of acoustic Doppler current profiler (aDcp) technology to obtain apparent bedload transport rates measurements, while water depths and velocities are concurrently acquired, lead to a new approach to map channel processing. This method enables the direct measurement of bedload transport, but might lead to biased measurements due to the suspended sediments loads (Rennie 2002, Rennie \& Millar, 2004).

Most sediment transport models used to simulate braided rivers are depth-averaged models because three-dimensional (3D) morphodynamics modeling tends to be computationally expensive and 3D calibration data are often unavailable (Lane et al., 1999). However, braided river flows are strongly affected by $3 \mathrm{D}$ effects and bedload transport tend not to be handled effectively using averaged cross-sectional or channel properties data. On the other hand, twodimensional (2D) model accounts for secondary circulation and appropriate transverse and longitudinal bed shear stress vectors which can contribute to represent adequately the 3D complexity of morphodynamics. Bedload rate increases nonlinearly with bed shear stress in excess of the critical shear stress for particle entrainment (Li et al., 2008). In many braided rivers, bedload transport is, however, not limited to bankfull flow, and bedload transport is observed at relatively low flows, far below bankfull conditions (Williams et al., 2015). Conventional 2D morphodynamics models use bed shear stress distribution to estimate bedload distribution. However, field evidence suggests that sediment supply locations, such as eroding banks, can dictate 
bedload transport pathways (Rennie 2012, Williams et al. 2015). Thus, it is unclear if the use of bed shear stress distributions is appropriate for 2D simulations of braided river morphodynamics.

\section{METHODOLOGY}

\subsection{Study area}

The paper represents the first step in comparing bedload transport pathways simulated with a morphodynamic model with observed bedload pathways. The paper discusses the initial calibration of a model that was developed to simulate channel change in a $300 \mathrm{~m}$ anabranch of the braided Rees River (New Zealand). The Rees catchment is located on the Southern Island of New Zealand (Fig. 1) and covers an area of $420 \mathrm{~km}^{2}$ east to the Southern Alps (Williams et al., 2015). The Rees River is subject to active sediment supply, resulting in transport limited conditions (Cook, 2013). Flow of the Rees River is strongly affected by storms, and discharge was measured every 15 minutes from September 2009 to March 2011 at the Invincible gauging station, located about $8 \mathrm{~km}$ upstream of the study area (Fig. 1) The steep slopes of the catchment combine with thin soil cover generate steep rising limbs (Williams et al., 2013). During the mentioned period, the mean discharge of the Rees was 20 cubic meters per second (cms), while the maximum discharge was 475 cms.
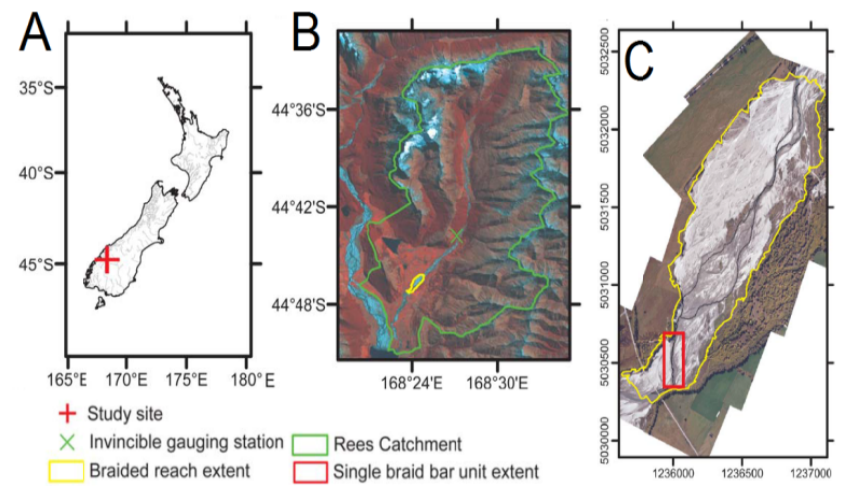

Figure 1. A. Study area location. B. Rees catchment extend. C. Extend of study area (adapted from Williams et al., 2013)

\subsection{Data Collection}

The field surveys were reported in Williams et al. (2015). The acoustic surveys were acquired using a Sontek M9 RiverSurveyor (3.0 MHz transducer) mounted on a Sontek Oceanscience Riverboat trimaran. This apparatus was used to measure depths and velocities, as well of track, from which bedload transport pathways were derived. The trimaran was deployed using two ropes and operators, standing on opposite sides of the river, moved the platform from one bank to the other in zigzag transects, with a nominal 1 to $2 \mathrm{~m}$ streamwise spacing. The position of the trimaran was obtained from a Novatel RTKGPS, which was corrected in real time from a base station with approximately $0.02 \mathrm{~m}$ positional accuracy. Topography of the study area was obtained from terrestrial laser scan (TLS) survey using a Leica HDS6100 phase based TLS. Each scan was georeferenced using two targets that were positioned using RTK-GPS. For each topographic surveys, between 14 and 20 scans were acquired, obtained from different locations within the study area, with a maximum distance of $50 \mathrm{~m}$ between each location. Surface material was obtained using the grid-count technique, equivalent to the pebble count technique proposed by Wolman (1954), leading to $\mathrm{D}_{16}, \mathrm{D}_{50}$ and $\mathrm{D}_{84}$ estimations. Intermediate (b) axes of 100 clasts were sampled at evenly spaced increments within a $1 \mathrm{~m}^{2}$ sampling frame. The sampling frame was positioned at 28 randomly selected sampling sites.

Topographic data, as well as velocity, depth, difference of digital elevation mode (DEM) and apparent bedload velocities data, taken from three of the surveys introduced in Section 2.2, were used as model boundary conditions and for comparison purposes. The surveys were carried out between February 7 and 162011 and are named Surveys B, C and D. The surveys were conducted following a $475 \mathrm{cms}$ event, representing the largest flood recorded on the Rees River over a period of 18 months (September 2009-March 2011) as shown in Figure 2 (Williams et al., 2015).

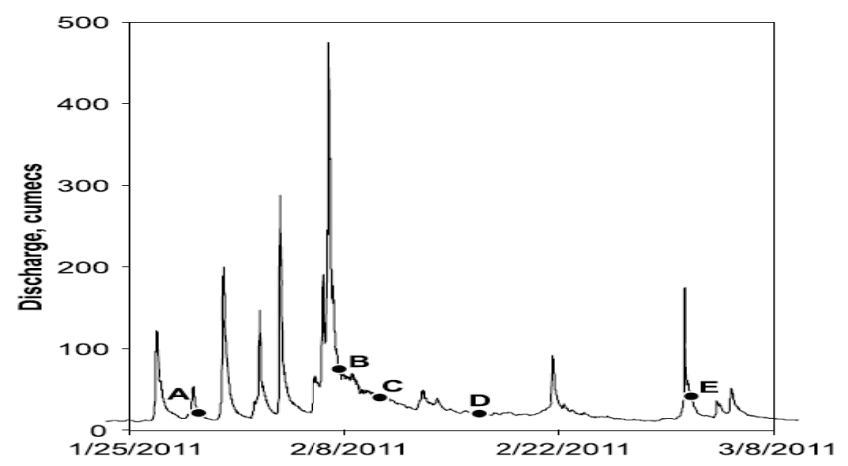

Figure 2. Rees River hydrograph showing occurrence of Surveys B, C and D (adapted from Williams et al., 2015)

Survey B was undertaken shortly after the peak flow which resulted in noticeable discharge difference $(4 \mathrm{cms})$ between the start and end of the survey while the flow remained somewhat constant during both Surveys C and D. Relevant information link to the conditions observed during all mentioned surveys are summarized in Table 1 . The uncertainty 
shown for the discharges in Table 1, refers to one standard deviation of the mean measured discharge from at least four aDcp transects (Williams et al., 2013).

Table 1. Characteristics of three water surveys of a Partial Braid Bar Unit of the Rees River (Williams et al., 2013)

\begin{tabular}{|l|l|l|l|}
\hline Survey & B & C & D \\
\hline Date and Time & $\begin{array}{l}07 / 02 / 2011, \\
16: 00\end{array}$ & $\begin{array}{l}10 / 02 / 2011, \\
7: 35\end{array}$ & $\begin{array}{l}16 / 02 / 2011, \\
17: 10\end{array}$ \\
\hline $\begin{array}{l}\text { Mean surveyed } \\
\text { depth (m) }\end{array}$ & 0.53 & 0.45 & 0.43 \\
\hline $\begin{array}{l}\text { Mean surveyed } \\
\text { depth-averaged } \\
\text { velocity (m/s) }\end{array}$ & 1.63 & 1.36 & 1.41 \\
\hline $\begin{array}{l}\text { Discharge at up- } \\
\text { stream bounda- } \\
\text { ry of the survey } \\
\text { (cms) }\end{array}$ & $35.6 \pm 0.9$ & $23.6 \pm 0.7$ & $14.4 \pm 0.7$ \\
\hline
\end{tabular}

The apparent bedload transport velocity during Survey C observed by Williams et al. (2015) is reproduced in Figure 3. Bedload transport pathways are evident in the observed spatial distribution, and will be used for validation of the morphodynamic modeling.

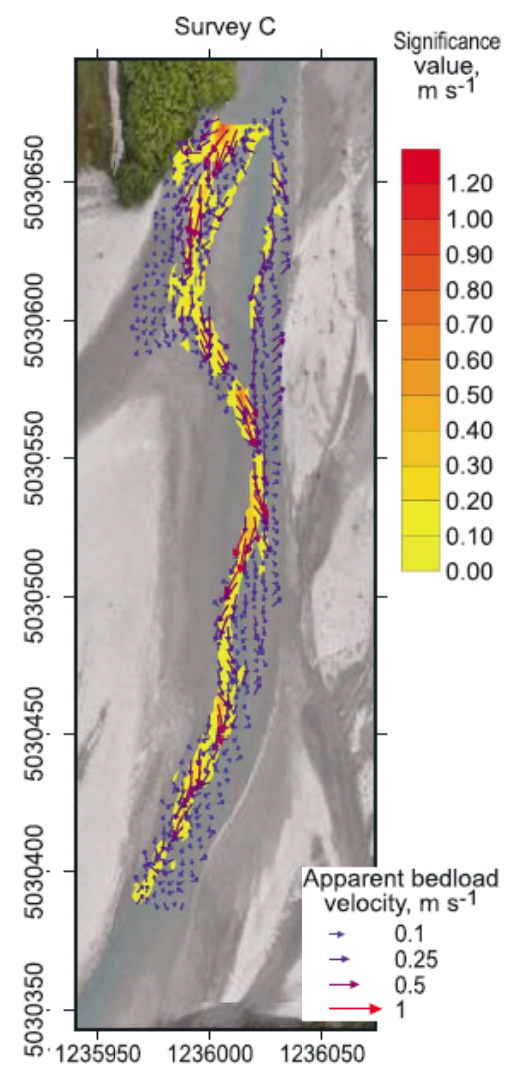

Figure 3. Apparent bedload transport velocity observed during Survey C (adapted from Williams et al., 2015)

\subsection{Morphodynamic Modeling}

\subsubsection{Delft3D Model}

Delft3D, an open-source model managed by Deltares, was used to model morphodynamics of an anabranch of the Rees River. This model was also used to simulate a $2.5 \mathrm{~km}$ long braided reach of the Rees River (Williams, 2014). Here, the Delft3D model was applied to simulate morphological change that occurred in-between three field surveys obtained on the falling limb of a major high flow. A 2D depth-averaged formulation was utilized, where Navier Stokes equations and Boussinesq approximation are solved by the model to simulate flow conditions under shallow water assumption. Delft3D supports several sediment transport formulas. Some of these formulas, including the default Van Rijn (1993) formula, consider both suspended and bedload transport separately. Some formulas look at total sediment transport, suspended and bedload combined, while others analyze bedload transport only. The primary focus of this study was to investigate the impact of the type of sediment transport formula used by the model. The formulas that were tested include the bedload transport formulas proposed by Wilcock-Crowe (2003) and Gaueman et al. (2009); the total transport formulas proposed by Meyer-Peter and Müller (1948); and the bedload and suspended transport formula proposed by Van Rijn (1984a,b,c). The Wilcock-Crowe and Gaueman models were formulated for transport of gravel-sand mixtures; the Meyer-Peter and Müller model was based on experimental observations of gravel transport, while the Van Rijn (1984a,b,c) was developed for transport of sand.

\subsubsection{General Model Setup}

Two scenarios were analyzed as part of the simulations. Scenario 1 analyzed morphodynamics that occurred between Surveys B and C (3 days), while Scenario 2 estimated morphological changes between Surveys C and D (6 days). For this present paper, only Scenario 1 will be considered. Unsteady discharge at the upstream boundary of the grid was estimated from the flow measured at the Invincible gauging station, located about $8 \mathrm{~km}$ upstream (Fig. 1). Assuming that the gauging station is exactly 8 $\mathrm{km}$ upstream of the study area, the traveling time of the water was estimated using the mean surveyed depth-averaged velocity, as shown in Table 1 . The time lags calculated are $1 \mathrm{~h} 22 \mathrm{~m}, 1 \mathrm{~h} 39 \mathrm{~m}$ and $1 \mathrm{~h} 35 \mathrm{~m}$ for Survey B to D, respectively. Table 2 shows the flow at the gauging station and the difference with the discharge recorded at the upstream boundary of the study area. The differences between the flows 
are, respectively, $47 \%, 62 \%$ and $70 \%$ for Survey B to $\mathrm{D}$, resulting in an average difference of $60 \%$.

Thus, it would be adequate to assume that the flow at the upstream boundary of the study area is about $60 \%$ smaller than at Invincible. Therefore, flow measured at Invincible, recorded at a frequency of 15 minutes, lagged by 90 minutes and reduced by $60 \%$, was set as the upstream discharge boundary. The loss in flow can be explained by the flow expansion across the wide braided network, as well as loss to groundwater.

Table 2. Flow at Invincible considering time lag

\begin{tabular}{|l|l|l|l|l|}
\hline Survey & $\begin{array}{l}\text { Date and } \\
\text { Time }\end{array}$ & $\begin{array}{l}\text { Discharge at } \\
\text { Invincible } \\
(\mathrm{cms})\end{array}$ & $\begin{array}{l}\text { Discharge at } \\
\text { the upstream } \\
\text { boundary } \\
(\mathrm{cms})\end{array}$ & $\begin{array}{l}\text { Diff. } \\
(\%)\end{array}$ \\
\hline B & $\begin{array}{l}07 / 02 / 2011, \\
14: 38\end{array}$ & 76.18 & 35.60 & $47 \%$ \\
\hline C & $\begin{array}{l}10 / 02 / 2011, \\
5: 56\end{array}$ & 37.79 & 23.60 & $62 \%$ \\
\hline D & $\begin{array}{l}16 / 02 / 2011, \\
15: 35\end{array}$ & 20.64 & 14.40 & $70 \%$ \\
\hline
\end{tabular}

Furthermore, a flow versus water level relationship, also known as QH-relationship, was used as the downstream boundary condition. Discharges for different water levels were calculated using constant channel slope and roughness values, along with the assumption of a horizontal water surface across the downstream boundary. For the given Rees anabranch, the mean slope is 0.004 , while the roughness value $\left(\mathrm{k}_{\mathrm{s}}\right)$ of $0.04 \mathrm{~m}$ was used. This roughness value was found to be optimal for the Rees River (Williams et al., 2013). The QH-relation was calculated based on a cross-section of the river, near the downstream boundary. The cross section was divided into segments, then the mean depth, area, conveyance and flow was calculated for all segments. From this, discharges were estimated for different horizontal water levels.

\subsection{Performance Assessment}

Water velocity, water depth and bed elevation predictions by the Delft3D model at the end of the scenario were compared to measured field data to assess the model's performance,. Predicted and measured data were compared by calculating the mean absolute error (MAE), as well as the root mean square error (RMSE) and the coefficient of determination $\left(\mathrm{r}^{2}\right)$. The error statistics mentioned are defined in Table 3, where $\mathrm{x}_{\text {modeled }}$ represents predicted depth, velocity or bed elevation and $\mathrm{x}_{\text {measured }}$ symbolizes measured depth, velocity or bed elevation.
Table 3. Error Statistics Formulation

\begin{tabular}{|c|c|}
\hline Error Statistic & Formula \\
\hline $\begin{array}{c}\text { Mean Absolute } \\
\text { Error (MAE) }\end{array}$ & $\mathrm{MAE}=\frac{\sum_{\mathrm{i}}^{\mathrm{n}}\left|\mathrm{x}_{\text {modeled }}-\mathrm{x}_{\text {measured }}\right|}{\mathrm{n}}$ \\
\hline $\begin{array}{c}\text { Root Mean } \\
\text { Square Error } \\
\text { (RMSE) }\end{array}$ & $\mathrm{RMSE}=\sqrt{\frac{\sum_{\mathrm{i}}^{\mathrm{n}}\left(\mathrm{x}_{\text {modeled }}-\mathrm{x}_{\text {measured }}\right)^{2}}{\mathrm{n}}}$ \\
\hline $\begin{array}{c}\text { Coefficient of De- } \\
\text { termination }\left(\mathbf{r}^{2}\right)\end{array}$ & $\mathrm{r}^{2}=1-\frac{\sum_{\mathrm{i}}^{\mathrm{n}}\left(\mathrm{x}_{\text {measured }}-\overline{\mathrm{x}_{\text {modeled }}}\right)^{2}}{\sum_{\mathrm{i}}^{\mathrm{n}}\left(\mathrm{x}_{\text {measured }}-\mathrm{x}_{\text {modeled }}\right)^{2}}$ \\
\hline
\end{tabular}

\section{RESULTS}

As introduced in Section 2.3.1., several sediment transport formulas were analyzed in order to identify the one generating the best predictions. The following section will present and analyze the model's predictions obtained from the different sediment transport formulas used.

\subsection{Sediment Transport Formula Sensitivity Analysis}

A major step of the calibration process was to identify the sediment transport formula which would most effectively model the morphodynamics that were observed between the field surveys. A total of four sediment transport formulas supported by Delft3D were analyzed, namely the Wilcock-Crowe (2003), Gaueman et al. (2009), Meyer-Peter and Müller (1948) and Van Rijn (1984a,b,c). The formulas were tested for Scenario 1 using the model setup described in Section 2.3.2. Note that here, the downstream boundary condition was forced using a fixed water level condition. Model predictions for water velocity and water depths were evaluated to the observed data. Moreover, the predicted bed levels at the end of the simulation were also compared to the surveyed elevations.

\subsubsection{Numerical Analysis}

The performances of all formulas are assessed numerically using the error statistics presented in Table 3 . First, the estimated water velocity field resulting from sediment transport estimations, thus an estimation of the morphological changes that occurred during the scenario, is compared to the observed flow of the Rees River measured during Survey C. Table 4 shows the statistics obtained from the different formulas for the water velocity component. Results shown in Table 4 suggest that the Meyer-Peter and Müller formula generates better correlation between the observed and modeled velocities. On the other hand, the Gaueman et al. formula resulted in smaller mean velocity errors, as both RMSE and MAE values are the smallest. 
Table 4. Numerical Performance of Sediment Transport Formula for Velocity Component

\begin{tabular}{|l|l|l|l|}
\hline Formula & $\mathrm{r}^{2}$ & $\begin{array}{l}\text { RMSE } \\
(\mathrm{m} / \mathrm{s})\end{array}$ & $\begin{array}{l}\text { MAE } \\
(\mathrm{m} / \mathrm{s})\end{array}$ \\
\hline Gaueman et al. & 0.0833 & 0.4291 & 0.3442 \\
\hline Wilcock-Crowe & 0.0456 & 0.4813 & 0.3565 \\
\hline Meyer-Peter and Müller & 0.2883 & 0.4891 & 0.3812 \\
\hline Van Rijn & 0.0936 & 0.6526 & 0.4926 \\
\hline
\end{tabular}

Secondly, the same statistics were calculated from the comparison between observed and modeled water depths, as show in Table 5. Results presented in Table 5 show that all formulas give similar mean depth errors, but that the correlation of the modeled depths with observed depths is somewhat better using the Van Rijn formula.

Table 5. Numerical Performance of Sediment Transport Formula for Depth Component

\begin{tabular}{|l|l|l|l|}
\hline Formula & $\mathrm{r}^{2}$ & $\begin{array}{l}\text { RMSE } \\
(\mathrm{m})\end{array}$ & $\begin{array}{l}\text { MAE } \\
(\mathrm{m})\end{array}$ \\
\hline Gaueman et al. & 0.1439 & 0.2195 & 0.1875 \\
\hline Wilcock-Crowe & 0.1504 & 0.2284 & 0.1905 \\
\hline Meyer-Peter and Müller & 0.0647 & 0.2225 & 0.1647 \\
\hline Van Rijn & 0.3512 & 0.2222 & 0.1809 \\
\hline
\end{tabular}

Finally, the last comparison looks at the statistics of the predicted bed levels after the simulation. Table 6 shows the statistics obtained from the different formulas for the bed level component. Results suggest that the Meyer-Peter and Müller formula leads to better estimation of the bed levels observed during Survey C. However, the other formulas give somewhat similar statistics than the ones obtained using the Meyer-Peter and Müller. Thus, analyzing the results using the numerical performances of each formula, the Meyer-Peter and Müller formula is the one that generates smaller mean errors for all analyzed variables.

Table 6. Numerical Performance of Sediment Transport Formula for Bed Level Component

\begin{tabular}{|l|l|l|l|}
\hline Formula & $\mathrm{r}^{2}$ & $\begin{array}{l}\text { RMSE } \\
(\mathrm{m})\end{array}$ & $\begin{array}{l}\text { MAE } \\
(\mathrm{m})\end{array}$ \\
\hline Gaueman et al. & 0.8129 & 0.3069 & 0.2666 \\
\hline Wilcock-Crowe & 0.8426 & 0.2665 & 0.2215 \\
\hline Meyer-Peter and Müller & 0.8323 & 0.2239 & 0.1709 \\
\hline Van Rijn & 0.7233 & 0.2615 & 0.2223 \\
\hline
\end{tabular}

\subsubsection{Visual Interpretation of the Results}

Observed and predicted distribution maps of all three variables analyzed in the last section will be presented in this section. This visual interpretation of the predicted results is done in order to confirm the results obtained in Section 3.1.1, as good statistics do not always translate into reasonable results. First, Figure 3 illustrates the velocities distribution map for the observed data, as well as the resulting velocity distribution maps for the tested sediment transport formulas. Note that water is flowing from top to bottom in the figure. One important note concerning the observed velocity distribution maps is related to the side channel on the right bank of the river predicted by the model (Fig. 3B-E). The channel was present at the time of the measurements but was not surveyed. When comparing the observed velocity field (Fig. 3A) to the other distribution maps, only the Van Rijn formula clearly indicates the presence of a bar near the upstream boundary and the flow that goes around this bar. Furthermore, the usage of the Van Rijn formula results in better sediment transport estimations as the resulting velocity field, obtained from the predicted morphology, is better estimated than with the other formulas.
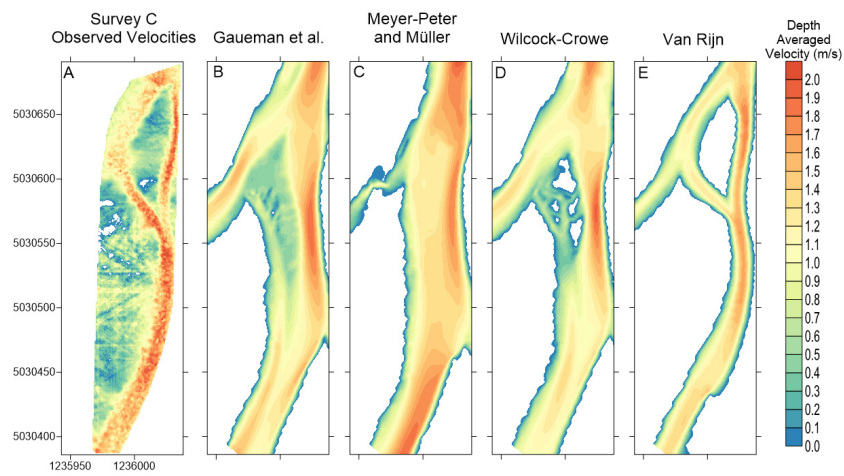

Figure 4. (A) Observed Velocities Distribution Map for Survey C. (B-E) Velocity Distribution Maps Resulting from Morphodynamics Simulation of Sediment Transport Formulas

Secondly, the same distributions maps were generated for the water depths, as shown in Figure 5. Similarly, the Van Rijn formula lead to better sediment transport estimations during the scenario, as the estimated water depth are in better agreement with the observed data.
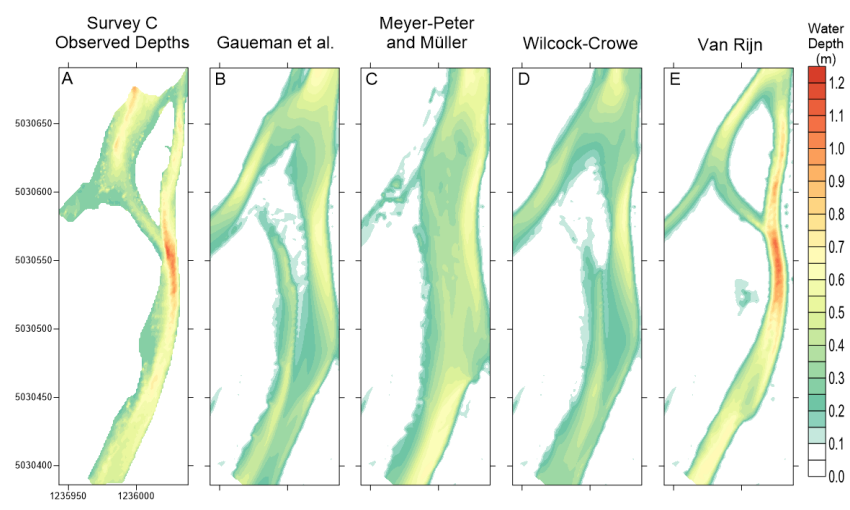

Figure 5. (A) Observed Depths Distribution Map for Survey C.

(B-E) Depths Distribution Maps Resulting from Morphodynamics Simulation of Sediment Transport Formulas 
The flow field is well replicated and the deep section of the river, downstream of the bar, is also well captured by the model. The final bed elevations distribution maps, shown in Figure 6, were computed to visually compare the bed elevations measured during Survey $\mathrm{C}$ to the predicted bed levels at the end of the scenario. The distributed bed levels confirm that the use of the Van Rijn formula leads to better estimation of the morphodynamics that occurred in between Surveys B and C, since the predicted bed elevations are well replicated, compared to the estimations obtained with the other formulas. Thus, even if the Meyer-Peter and Müeller formula generated better estimations from a numerical point of view (see Section 3.1.1), the distributed maps of water velocity, depths and bed levels demonstrate that the Van Rijn's predictions seems better for the given Rees River reach.
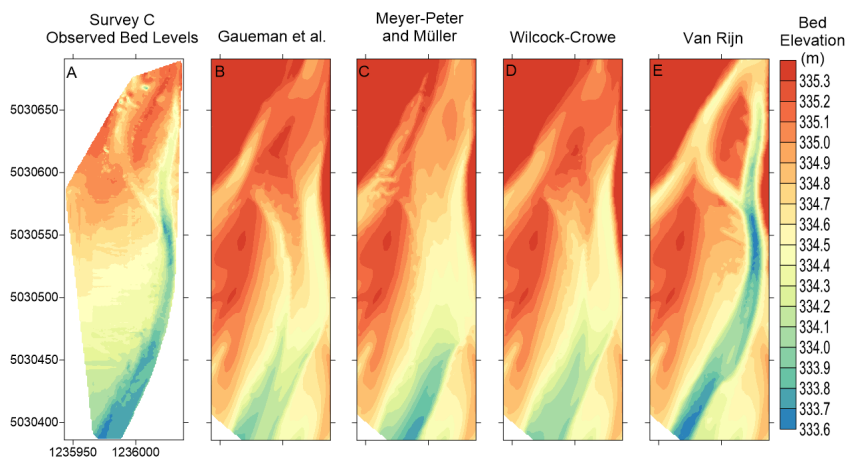

Figure 6. (A) Observed Bed Levels Distribution Map for Survey C. (B-E) Bed Levels Distribution Maps Resulting from Morphodynamics Simulation of Sediment Transport Formulas

In order to assess this given discrepancy between the numerical and visual results, the distributed difference maps between the observed and the modeled results were computed. First, Figure 7 illustrates the difference between the observed and modeled velocity fields for all tested formulas. As shown in Figure 4, velocity resulting from the sediment transport predictions using the Van Rijn formula were the ones which best replicated the general velocity field observed on site. Analyzing Figure 7, it appears that the low statistical values of the velocities obtained with the Van Rijn formula are due to the fact that the locations of the channels, following morphological changes estimated by the model, are slightly off the observed channels location. Thus, the velocity values, following morphological changes using the Van Rijn formula, are close to the observed velocities, as shown by the white and light red zones delimited by the black lines (Fig. 7D). However, the location of the predicted channels differ from the observed ones, as shown by the blue zones (Fig. 7D), which lead to the low statistical values listed in Table 4.

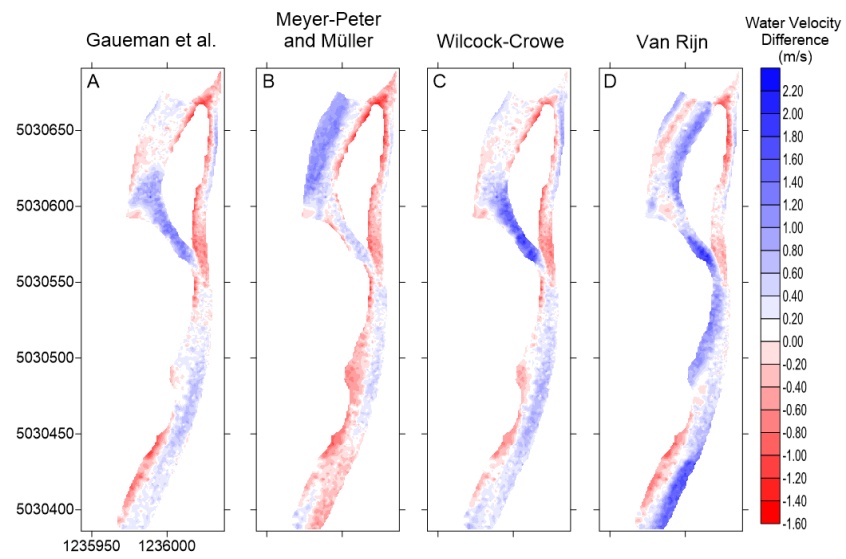

Figure 7. (A-D) Difference Distribution Maps Between Observed and Resulting Velocities from Morphodynamics Simulation for different Sediment Transport Formulas

As for, the Gaueman et al. and the WilcockCrowe formulas, they do not predict the confluence of the channels downstream of the bar, thus leading to high velocity differences in that zone. Although the Meyer-Peter and Müller formula yielded in morphological changes that best estimate water velocities, it lead to underestimation of the flow in the channel on the right side of the bar and to overestimation of the flow over the bar. A similar process was done to analyze the areas where the depth and bed level predictions by the model differ from the observed data. Figure 8 shows the difference between observed and modeled water depths for the Rees anabranch. The distributed map illustrating the water depths difference obtained using the Van Rijn formula (Fig. 8 D) shows that the predicted channels locations differ from the observed data.

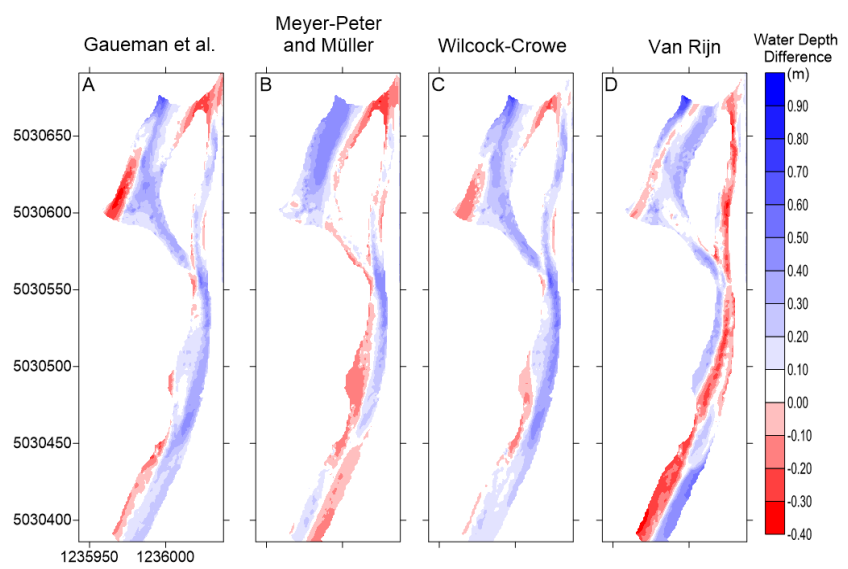

Figure 8. (A-D) Difference Distribution Maps Between Observed and Resulting Depths from Morphodynamics Simulation for different Sediment Transport Formulas

Moreover, the water depths in the main thalweg of the river are overestimated using the Van Rijn formula. The morphological changes estimated by Gaueman et al. and the Wilcock-Crowe formulas lead to underestimation of the flow depth in the anabranch. As for the Meyer-Peter and Müller formula, 
it leads to underestimation the flow depths in the areas where the velocity estimations were close to the observed velocities downstream of the bar (see Fig. 7B). Figure 9 shows the bed elevation differences between observed data and modeled results, as well as the difference between the DEM of Survey C and Survey B. All formulas, other than the Van Rijn, lead to overestimation of the bed elevations in the Rees anabranch. Indeed, the Van Rijn formula leads to underestimation of the riverbed throughout the anabranch, while the bed elevation predictions towards the left bank of the river at the downstream end of the reach are overestimated. However when comparing the modeled results (Fig. 9B-D) to the DEM of difference between Survey $\mathrm{C}$ and B (Fig. 9A), only the Van Rijn formula's predictions concerning the erosion and sedimentation areas are comparable to what was observed. Similar to the observation that was made analyzing Figure 7, the low statistical values obtained using the Van Rijn formula (presented in Table 4 to 6), are linked to misprediction in the channel locations, since the resulted velocities, depths and bed levels do favor the Van Rijn formula when the results are visually compared to the observed data (Figs 3-5).

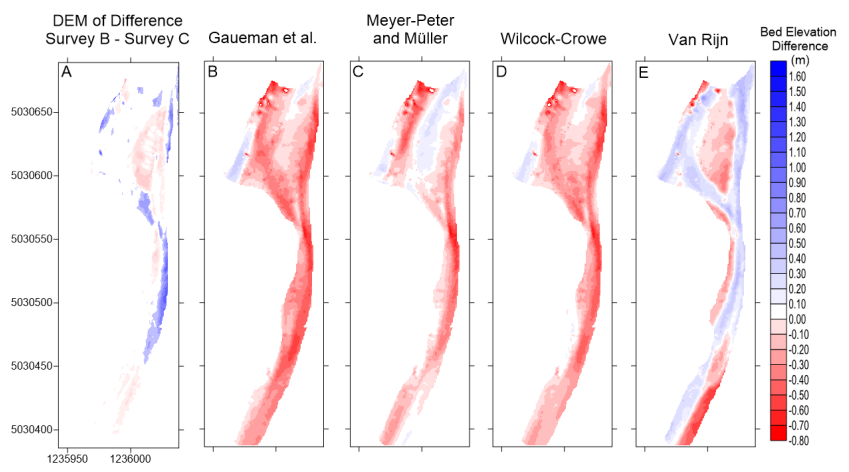

Figure 9. (A-D) Difference Distribution Maps Between Observed and Resulting Bed Elevations from Morphodynamics Simulation for different Sediment Transport Formulas

\section{DISCUSSION}

The use Van Rijn's sediment transport formula lead to the best agreement between the results of the Delft3D model and the observed data gathered on the Rees River. It is interesting that, out of the formulas that were tested, the Van Rijn's morphodynamics predictions are the closest to the morphological changes that were noticed in the gravel bed Rees River, as it was developed for sandy rivers. The good morphological predictions by the Van Rijn's for the Rees River can be explained by the simple correlation that links excess shear stress and non-dimensional grain size. Thus, even though the Van Rijn formula was derived from work related to sandy rivers, it still can adequately predict morphodynamics at a single anabranch scale in gravel bed rivers.

As previously mentioned, this paper introduced the morphodynamic model which was used to compare observed bedload transport pathways of the Rees River anabranch to modeled bedload transport results. Ultimately, this work endeavors to investigate whether shear stress distributions are useful for predicting bedload transport pathways, as well as attempting to validate the bedload transport pathways observed on the field. The modeled bedload pathways, obtained at the end of the simulations, were compared to the pathways derived from field observations through a vector correlation analysis (Crosby et al. 1993, Rennie and Millar 2004). The 2D bedload spatial distribution predicted by the Van Rijn model was significantly correlated to the spatial distribution of apparent bedload velocity observed by Williams et al. (2015). The vector correlation results will be used to guide further model refinements.

\section{CONCLUSION}

The present paper presented the initial calibration of a Delft3D model used to simulate morphological changes occurring in a $300 \mathrm{~m}$ anabranch of New Zealand's Rees River. This model will ultimately be used to assess whether shear stress distribution is a useful tool to predict bedload transport pathways. Several sediment transport formulas that are implemented in Delft3D were tested to identify which one would best reproduce (predict) field measurements. Out of the four sediment transport formulas that were investigated, the Meyer-Peter and Müller formula lead to smaller mean errors for all analyzed variables, namely water velocity, water depth and bed elevation. Thus, a point-to-point comparison between observed and modeled data leads to better statistics with the Meyer-Peter and Müller formula. On one hand, the velocities, depths and bed levels are best reproduced by the Van Rijn formula when the distribution maps are used to compare modeled results to the observed data. On the other, low statistics were obtained when comparing the Van Rijn's results on a point-to-point basis to observed data. However, it was found that the lower statistical values obtained with Van Rijn's formula were due to misprediction of the channel locations. Consequently, the Van Rijn's formula was found to be the one leading to best agreement between observed data and model predictions, despite occasionally leading to lower statistical values. 


\section{REFERENCES}

Ashmore, P., (2013). Morphology and dynamics of braided rivers In Treatise on Geomorphology, edited by John F. Shroder, Academic Press, San Diego, Vol. 9, 289-312

Belletti, B., Dufour, S., and Piégay, H. (2015). What is the Relative Effect of Space and Time to Explain the Braided River Width and Island Patterns at a Regional Scale?. River Research and Applications, 31(1), 1-15.

Chalov, S. R., and Alexeevsky, N. I. (2015). Braided rivers: structure, types and hydrological effects. Hydrology Research, 46(2), 258-275.

Church, M. (1992). Channel morphology and typology. In: Calow, P. and Petts, G.E. (eds.) The Rivers Handbook. Blackwell, Oxford, pp. 126-143

Cook, S. J., D. J. Quincey, and J. Brasington (2013). Geomorphology of the Rees Valley, Otago, New Zealand, J. Maps

Crosby D.S., Breaker L.C., and Gemmill W.H. (1993). A proposed definition for vector correlation in geophysics: theory and application. Journal of Atmospheric and Oceanic Technology 10: 355-367.

Gaeuman, D., Andrews, E. D., Krause, A., and Smith, W. (2009). Predicting fractional bed load transport rates: Application of the Wilcock-Crowe equations to a regulated gravel bed river. Water resources research, 45(6).

Lane, S. N., Bradbrook, K. F., Richards, K. S., Biron, P. A., and Roy, A. G. (1999). The application of computational fluid dynamics to natural river channels: three-dimensional versus two-dimensional approaches. Geomorphology, 29(1), 1-20.

Li, S. S., Millar, R. G., and Islam, S. (2008). Modeling gravel transport and morphology for the Fraser River gravel reach, British Columbia. Geomorphology, 95(3), 206-222.

Meyer-Peter, E., and Müller, R. (1948). Formulas for bed-load transport. IAHR.

Rennie C. D. (2002). Non-invasive measurement of fluvial bedload transport velocity using an acoustic Doppler current profiler. PhD thesis, Department of Civil Engineering, University of British Columbia, Canada.

Rennie, C.D. (2012). Mapping water and sediment flux distributions in gravel-bed rivers using aDcps. in Gravel-bed rivers: processes, tools, environments. Church, M., Biron, P. and Roy, A.G., editors. Chichester, John Wiley \& Sons. ISBN 978-0-470-68890-8.

Rennie, C. D., and R. G. Millar (2004). Measurement of the spatial distribution of fluvial bedload transport velocity in both sand and gravel, Earth Surf. Processes Landforms, 29(10), 1173-1193

Van Rijn, L. C. (1984a). Sediment transport, part I: bed load transport. Journal of hydraulic engineering, 110(10), 14311456.

Van Rijn, L. C. (1984b). Sediment transport, part II: suspended load transport. Journal of hydraulic engineering, 110(11), 1613-1641.

Van Rijn, L. C. (1984c). Sediment transport, part III: bed forms and alluvial roughness. Journal of hydraulic engineering, 110(12), 1733-1754.

Van Rijn, L. C. (1993). Principles of sediment transport in rivers, estuaries and coastal seas (Vol. 1006). Amsterdam: Aqua publications.

Wilcock, P. R., and Crowe, J. C. (2003). Surface-based transport model for mixed-size sediment. Journal of Hydraulic Engineering, 129(2), 120-128.

Williams, R. D., (2014). Two-dimensional Numerical Modelling of Natural Braided River Morphodynamics. PhD Thesis, Aberystwyth University, Aberystwyth, Ceredigion, UK

Williams, R. D., Brasington, J., Hicks, M., Measures, R., Rennie, C. D., and Vericat, D. (2013). Hydraulic validation of two-dimensional simulations of braided river flow with spa- tially continuous aDcp data. Water Resources Research, 49(9), 5183-5205

Williams, R. D., C. D. Rennie, J. Brasington, D. M. Hicks, and D. Vericat (2015), Linking the spatial distribution of bed load transport to morphological change during high-flow events in a shallow braided river, J. Geophys. Res. Earth Surf.,120, 604-622

Wolman, M. G. (1954), A method of sampling coarse bed material, Trans., Am. Geophys. Union, 35, 951-956. 